\title{
Research on Industrial Structure Change and Its Natural Environment Effect
}

\author{
Fei $\mathrm{Li}^{1, \mathrm{a}}$ \\ ${ }^{1}$ Liaoning School of Economics and Political Science, Shenyang, china \\ abjlifei@163.com
}

\begin{abstract}
Keywords: Industrial structure; Industrial tranformation; Natural environment effect
\end{abstract}
Abstract. The research on the influence of the structural evolution of industrial structure on natural environment is a kind of useful exploration for the industrial structure optimization research under the sustainable development theory. In particular, the demand on resource energy of our country at present is larger and larger, the conflict between economic development and resource supply is increasingly prominent, the environmental issues are increasingly obvious, so the influence of deep analysis on the evolution of industrial structure on natural environment has necessity and urgency. The development and change track of industrial structure in Liaoning province and the influence of the development of different industries on natural environment are analyzed in this text, and the change of industrial structure in this province and its natural environment effect since 1991 are calculated by utilizing the influence indexes of different industries on natural environment. We think from the text that the industrial structure of Liaoning province has changed greatly since 1991, experiencing two obvious industrial transformation; the influence of industrial structure on natural environment since 1991 belonged to medium, having two large fluctuation and reduction-to-rebound phenomenon; in particular, the ascensional range since 2000 was very large, reaching a new record; the industrial transformation task was rather arduous, needing the implementation of long-acting industrial policy basing on natural environment protection.

\section{Introduction}

The industrial structure is an important tache between economic activity of human being and natural environment. The development of regional industry and its combination type as well as strength change not only promote the economic prosperity of regional society, but also exert important influence on natural environment. Since the proposal of industrial transformation research program in International Human Dimensions Programme on Global Environmental Change (IHDP), international sociologists and scientists have paid extensive attention rapidly, so as to reveal the research of urging industrial system to turn to industrial transformation (IT) under the constraints of sustainable development social mechanism and driving force of human being as well as resource and environment, which has become an international leading issue with multidisciplinary comprehensive research.

Liaoning province is the earliest and the most important old industrial base in our country, with an extensive economic development model of long-time resource consumption and environmental damage. Therefore, this province has a large number of resource environment issues, nervous relationship of economic growth and environment, and ordeal faced by regional sustainable development. Taking Liaoning province as an example, the influence of industrial structure change on the environment is analyzed, so as to provide scientific reference for industrial structure adjustment and revitalization of Liaoning old industrial base.

\section{Influence of development of different industries on environment}

\section{Influence of primary industry on natural environment}

The advantages of the influence of primary industry on natural environment include that it takes green plants as production objects, being an important barrier for natural environment, so as to control 
$\mathrm{CO}_{2}$ and reduce the emission load of $\mathrm{CO}_{2}$ in atmosphere. The disadvantages include unreasonable reclamation and utilization in planting industry resulting in water and soil loss, land salinization and desertization, usage of pesticides and fertilizers and other agricultural chemicals resulting in all kinds of pollution like water pollution, soil pollution and air pollution and etc, But in general, there are both advantages and disadvantages in the influence of the development of primary industry on the natural environment of the region, and the influencing depth and width of primary industry on the environment are relatively limited.

\section{Influence of secondary industry on natural environment}

The production characteristics of secondary industry determine that its energy consumption, material consumption level and pollutant generation and emission level are far more than those of primary industry and tertiary industry. The rapid development of secondary industry, especially extractive industry, manufacturing industry and other heavy industries, takes a large amount of consumptive mineral, energy and other non-renewable resources as the price. As the auxiliary product produced by industrial production, industrial pollutant has threatening effect on natural ecological environment. This kind of threatening pressure is accumulated in absolute amount over a long period, which will lead to gradual deterioration of natural environment.

\section{Influence of tertiary industry on natural environment}

The influence of tertiary industry on the environment is smaller than that of primary industry or secondary industry. The dependency of tertiary industry on the environmental resources is very small, but the development of industries like tourist industry, transportation industry, catering industry and so on has direct influence on the environmental quality. Adverse effects like waste water pollution, noise disturbing the residents, automobile exhaust pollution and so on will be produced if there is ill management, which will lead to the disappearance of some natural landscape.

\section{Industrial structure change of Liaoning province}

With continuous development of economy and constant evolution of market economic system, the industrial structure of Liaoning province also changes greatly. The changes of three industries on GDP contribution rate from 1991 to 2012, so as to measure the proportion change of three industries in Liaoning province. We can see from Fig. 1 that the proportion of primary industry on GDP contribution was declining on the whole, the proportion of output value in 1998 was the largest, being $17.7 \%$, and that in 2001 and 2009 was the smallest, being $2.0 \%$; secondary industry was still in a leading position, but the proportion of output value was rising on the whole, that in 2000 was the largest, being $65.4 \%$, that in 1991 was the smallest, being $41.2 \%$, the total rising proportion was small though it was fluctuated during this period, it was in a rising status from 2005 to 2011 basically, the proportion of output value in 2011 reached $62.1 \%$; tertiary industry develops slowly, the proportion of it was declining on the whole, and that of tertiary industry in 1991 to 2012 was larger than that of primary industry. The proportion of tertiary industry in 1991 to 1994 was declining obviously, after that, the proportion was increasing gradually. The proportion in 1994 to 2001 was rising, and the maximum one reached $49.8 \%$ in 2001, after that, it was declining to $39 \%$ in 2012.

\section{Environment effect evaluation on industrial structure change of Liaoning province}

\section{Evaluation method}

The development of different industries have different influencing methods and degrees on natural environment, so we can divide the industrial structure of Liaoning province into the following matters: primary industry can be divided into planting industry, forestry, animal husbandry and fishery; secondary industry can be divided into light industry, heavy industry, and construction industry, tertiary industry can be divided into transportation industry and other industries.

(1) Clear and definite the influence weight of industrial structure on natural environment. Taking the difference of influencing degree and depth of the development of different industries on natural 
environment as the basis, measure the relative intensity of the development of different industries on natural environment, influence coefficients of different industrial types on natural environment in section of [1,5], and proportional relation reflecting natural environment influence on the proportion of output of each industrial unit in turn. The larger the coefficient is, the larger the adverse impact of the industry on the environment is (Table 1).

Table 1 Influence coefficients of different industrial types on natural environment

\begin{tabular}{lcccccccc}
\hline Name of industry & $\begin{array}{c}\text { Planting } \\
\text { industry }\end{array}$ & Forestry & $\begin{array}{c}\text { Animal } \\
\text { husbandry }\end{array}$ & Fishery & $\begin{array}{c}\text { Light } \\
\text { industry }\end{array}$ & $\begin{array}{c}\text { Heavy } \\
\text { industry }\end{array}$ & $\begin{array}{c}\text { Construction } \\
\text { industry }\end{array}$ & $\begin{array}{c}\text { Transportation } \\
\text { industry }\end{array}$ \\
$\begin{array}{l}\text { Influence } \\
\text { coefficients }\end{array}$ & 3 & 2 & 2 & 2 & 4 & 5 & 3 & 4 \\
\hline
\end{tabular}

(2) Calculate the influence index of regional industrial structure on the total natural environment. Perform weighted summation on the proportion of output value according to corresponding influence coefficients on natural environment of all industrial types, so as to obtain the influence index of regional industrial structure on the total natural environment (IIISNE) to represent the total influence and disturbance state of a certain industrial structure on the regional natural environment (Table 2).

Table 2 Grading of influence index of industrial structure on natural environment

\begin{tabular}{|c|c|c|c|c|c|}
\hline Influence index of natural environment & $1-1.5$ & $1.5-2.5$ & $2.5-3.5$ & $3.5-4.5$ & $4.5-5$ \\
\hline Grading & Weak & $\begin{array}{l}\text { Relatively } \\
\text { weak }\end{array}$ & Medium & $\begin{array}{c}\text { Relatively } \\
\text { serious }\end{array}$ & Serious \\
\hline
\end{tabular}

IIISNE $=\mathrm{P} 1 \mathrm{~W} 1+\mathrm{P} 2 \mathrm{~W} 2 \ldots \ldots+\mathrm{P} 9 \mathrm{~W} 9$

In which, P1P2...P9 refers to influence coefficient of each industrial type on natural environment, and $\mathrm{W} 1 \mathrm{~W} 2 \ldots \mathrm{W} 9$ refers to the proportion of output vlaue of corresponding each industry. In the end, perform comprehensive quantitative evaluation on natural environment effect of regional industrial structure change by comparing the difference of numerical value of IIISNE at different periods. According to the following formula, obtain the influence coefficients of three industries on natural environment based on influence coefficients of different industrial types on natural environment in Table 3, i.e. Pprimary industry is 2.25 , Psecondary industry is 4 , and Ptertiary industry is 2.5 .

$$
\begin{aligned}
& \mathrm{Ppi}=(\mathrm{P} 1+\mathrm{P} 2+\mathrm{P} 3+\mathrm{P} 4) / 4 \\
& \mathrm{Psi}=(\mathrm{P} 5+\mathrm{P} 6+\mathrm{P} 7) / 3 \\
& \mathrm{Pti}=(\mathrm{P} 8+\mathrm{P} 9) / 2 \\
& \text { IIISNE}=\mathrm{PpiW} \text { pi+PsiWsi+PtiWti }
\end{aligned}
$$

\section{Result analysis}

Perform quantitative evaluation on natural environment effect of industrial structure change of Liaoning province since 1991 by performing time series analysis and establishing influence index of regional industrial structure on total natural environment. It is widely believed that the development of primary industry has larger influence on the environment and obvious improvement effect; the development of secondary industry has destructive effect on the quality of water environment, atmospheric environment and solid environment; the development of tertiary industry has destructive effect on the quality of atmospheric environment. Calculate the influence index of different years on natural environment according to the calculation method of IIISNE index, and perform the evaluation by combining with grading standard of influence index on natural environment. We can see that the index of IIISNE in Liaoning province belongs to medium level within studied time with obvious 
evolution track, and three wave crests are respectively appeared in 1993, 2001, and 2011, which are existed in such two obvious wave trough periods. The influence index evolution of natural environment in Liaoning province has the following features: (1)The consistency is existed in change trend of natural environment effect track caused by industrial change track and industrial transformation, with obvious "wave"; (2)The natural environment change caused by industrial change in time domain falls behind the industrial structure transformation; (3)The influencing periodicity of natural environment of industrial structure change is relatively stable.

\section{Development countermeasure on new industrial structure of Liaoning province}

\section{Promote diversified development of ownership structure}

The diversification of ownership structure is the outstanding feature of industrial structure change of Liaoning province in recent years. Moreover, the competition and cooperation among enterprises with different ownership structures are important driving forces to build a new industrial structure. Therefore, it is necessary to reinforce the strength of state-owned-enterprises reform and restructuring, vigorously develop the non-public economy, support the development of middle and small-sized enterprises of private economy, and encourage the active participation of private economy in state-owned-enterprises reform and restructuring to cultivate a healthy and vigorous micro subject for the implementation of new industrial structure development model.

\section{Strengthen the policy guidance of industrial development}

It is to actively guide the competition and cooperative relationship among internal enterprises in new industrial structure development modes like modularization, aggregation and circular economy park and so on, speed up the development of social service institutions like scientific and technological intermediary and industry association and so on in the industry, and carry out consultation, information exchange and cooperative relationship among associated industries for enterprises; carry out training activities for entrepreneurs, improve the overall qualities of entrepreneurs, enhance the innovation consciousness of entrepreneurs, and cultivate the innovative cultural atmosphere of industrial development; guide the healthy development of the industry and enhance the whole competitiveness of the industry through policy regulation of energy price like water and electricity as well as perfection of land examination and approval system.

\section{Explore integrated management mode of environment}

Integrated management of environment shall mainly include the integration of four aspects: First, inter-departmental integration, namely trans-department management; second, inter-territorial integration, namely trans-regional management; third, integration of management content; fourth, integration of management object. Environmental issues of urban agglomeration in the central part of Liaoning province include water pollution, atmospheric pollution, soil pollution, etc., involving several levels like urban environment, rural environment and watershed management and so on. Therefore, it is necessary to build an integrated management mode of environment basing on urban, rural and watershed management.

\section{Acknowledgements}

This work was financially supported by the national social science foundation general project "Research on the Environmental Effect of Regional Industrial Structure Transformation" (No: 13BJY067)

\section{References}

[1] Galeotti1 M. Manera M. Lanza A. On the Robustness of Robustness Checks of the Environmental Kuznets Curve Hypothesis,Environmental and Resource Economics,2009,42 (4) :551-574. 
[2] Egli H. Steger T. M. A Dynamic Model of the Environmental Kuznets Curve:Turning Point and Public Policy,Environmental and Resource Economics,2007,36 (1) :15-34.

[3] Stern D. Explaining changes in global sulfur emi ssion: an econometric decomposition approach ,Ecological Economics , 2002,42 (1-2): 201-220 